\title{
Redistribution of charged aluminum nanoparticles on oil droplets in water in response to applied electrical field
}

\author{
Mengqi Li and Dongqing Li* \\ Department of Mechanical and Mechatronics Engineering, University of Waterloo, \\ Waterloo, Ontario, Canada N2L 3G1 \\ *Corresponding author, Address: 200 University Ave. West, Waterloo, Ontario, N2L 3G1 \\ Email: dongqing@uwaterloo.ca (D. Li)
}

\section{Statement}

The final publication is available at Springer via http://dx.doi.org/ 10.1007/s11051-016-3390-5. 


\begin{abstract}
Janus droplets with two opposite faces of different physical or chemical properties have great potentials in many fields. This paper reports a new method for making Janus droplets by covering one side of the droplet with charged nanoparticles in an externally applied DC electric field. In this paper, aluminum oxide nanoparticles on micro-sized and macro-sized oil droplets were studies. In order to control the surface area covered by the nanoparticles on the oil droplets, the effects of the concentration of nanoparticle suspension, the droplet size as well as the strength of electric field on the final accumulation area of the nanoparticles are studied.
\end{abstract}

Key Words: Janus droplet, charged nanoparticles, electrical field, particle redistribution, oil droplet in water 


\section{Introduction}

Janus is a Roman God who has two different faces, and the Janus droplets are referred to the droplets whose two hemispheres' surfaces have different physical or chemical properties. Due to this special feature, various applications of Janus droplets have been reported, including fabrication of the Janus particles, micro-motors and micro-reactors. Janus particles have been studied in the past decades (Binks and Fletcher 2001; Roh et al. 2005; Nisisako et al. 2006; Nisisako and Torii 2007; Daghighi et al. 2011; Wang et al. 2011), and can be used as selfpropelling particles (Jiang et al. 2010; Bickel et al. 2013), emulsifiers (Binks and Fletcher 2001; Nonomura et al. 2004; Glaser et al. 2006), micro-valve (Daghighi and Li 2011), and pixels in electronic papers (Nisisako et al. 2006; Walther and Müller 2008). One of the general methods to form Janus particles is bipolar electrochemistry (Fattah et al. 2011; Loget et al. 2011; Loget et al. 2012a; Loget et al. 2012b; Ongaro et al. 2014; Sopha et al. 2014). Under a strong electric field, conducting particles can be polarized and electrochemical reactions occur at two ends of the particles, which will result in different properties at opposite sides of the particles and hence the generation of Janus particles. With this method, Loget et al. (2012b) synthesized carbon-metal Janus particles successfully by immersing carbon beads into metal salt solutions. Janus particles can also be produced by solidification of Janus droplets, for example, by a microfluidic photopolymerization system (Nie et al. 2006; Wurm and Kilbinger 2009; Yoon et al. 2011; Lone and Cheong 2014). In such a system, two liquid monomers mixed with a photo-initiator are used to generate Janus droplets first. After the formation of Janus droplets, UV light is applied to lock the shape of the Janus droplets and leads to solid Janus particles. With this method, the size, fraction of monomers and the materials of the Janus particles can be altered flexibly. For example, Nie et al. (2006) synthesized Janus particles with different portions of monomers by adjusting the ratio of the flow rate of the two liquid monomers. Janus droplets can be employed as micro-motors to transport certain samples from one place to another (Jeong et al. 2015; Shklyaev 2015). Shklyaev (2015) studied the self-propulsion of Janus droplets in a surfactant solution theoretically. The function of the self-propulsion velocity in terms of the internal viscosities and the solutocapillary constants was derived. Jeong et al. (2015) experimentally studied the self-propulsion of the Janus droplets with a liquid crystal compartment and a polymer compartment in a concentrated surfactant solution. Janus droplets can also be used as microreactors (Shardt et al. 2014) without the need of additional steps for droplet generation and 
merging. Ahn et al. (2010) generated Janus droplets as micro-reactors to enhance mixing of the reagent and reactant in microfluidics.

Despite the many applications of Janus droplets, the limited fabrication methods restrict its further development. Currently, the one-step high energy mixing method (Torza and Mason 1970; Hasinovic et al. 2011; Hasinovic and Friberg 2011; Friberg et al. 2013; Ge et al. 2014; Zarzar et al. 2015) and the microfluidic method (Utada et al. 2005; Nie et al. 2006; Pannacci et al. 2008; Guzowski et al. 2012) are the two main techniques to form Janus droplets. For the one-step high energy mixing method, two immiscible oils are added into an aqueous surfactant solution first. Then the Janus droplets composed of the two immiscible oils can be formed by putting the mixture into a vibration mixer. The topology of the Janus droplets can be varied with the interfacial tension and volume ratios of the oils. Although Janus droplets can be easily generated with this approach, the size of them is hard to control during the emulsification. The microfluidic method overcomes this disadvantage and can fabricate Janus droplets with accurate size. The mechanism of this method is as follows: two immiscible liquid monomers flow in a central channels of a microfluidic chip, and an aqueous liquid flows in two side channels. When the thin stream of the two monomers is forced to flow through a narrow orifice, the shear force generated by the aqueous phase will cause the thin stream of the two monomers to breaks up and form Janus droplets. The proportion of different monomers in the droplets can be changed by adjusting the volume flow rates of the two immiscible liquid monomers, and the size of the droplets can be controlled by regulating the volume flow rates of the monomers and the aqueous liquid. Apart from the two methods discussed above, Bormashenko et al.(2011) reported another way to manufacture Janus droplets. In their experiment, two droplets coated with different powders, carbon black and polytetrafluoroethylene, were inserted into a dish. The Janus droplet can be formed by vibrating the dish to make the two droplets merge with each other.

It is well-known that particles can be used to modify the physical or chemical properties of the interfaces. For example, the optical properties of the oil-water interface will change if a nanoparticle monolayer film forms at the interface. Yogev et al. (1991) and Luo et al. (2012) reported that the transparent oil-water interface would reflect light and perform like a mirror with the presence of metal nanoparticles at the interface. Furthermore, particles can low the interfacial free energy of the oil-water interface, which can be used as emulsifier to stabilize the emulsions 
(Levine et al. 1989; Chevalier and Bolzinger 2013). The chemical properties of the interface can also be modified, depending on the properties of the particles covering it (Schaming et al. 2011; Edel et al. 2013). Therefore, Janus droplets can be fabricated by introducing particles to partially cover the droplet surface. With this consideration, Xu et al.(2013) generated Janus droplets in water with polydopamine (PDA) particles. They found that the $\mathrm{OH}^{-}$and the PDA particles occupied separate areas on the droplets, and Janus droplets with different surface coverage by PDA particles can be formed by adjusting the $\mathrm{pH}$ value of the solution. For the oil droplet immersed in leaky dielectric liquid, the particles trapped on the surfaces of the oil droplet can be driven to move by the electrohydrodynamic (EDH) flows inside and outside the oil droplet and assemble into a "ribbon-like" structure on the oil droplet (Dommersnes et al. 2013; Rozynek et al. 2014a; Ouriemi and Vlahovska 2015; Amah et al. 2016). By coalescing two oil droplets with ribbon-like structures made of different particles, a Janus droplet was generated by Rozynek and his colleagues(2014b).

The above-mentioned methods may not be suitable for producing Janus droplets carrying opposite surface charges on the two hemispheres. For example, Janus droplets fabricated by the one-step high energy mixing method consist of two immiscible oils, both carry negative charges when contacting with water. However, for the Janus droplets carrying opposite surface charges on their two hemispheres can be used in many areas. For example, under externally applied electrical field, the electro-osmotic flows from the two sides of such a Janus droplet are in the opposite directions and will result in vortices around the droplet. This phenomenon can be used to control the electrokinetic motion and separation of Janus droplets by size and by surface coverage of different charges. Furthermore, by adding certain curing agent, Janus droplets can be solidified and bipolar solid Janus particles can be produced which can be used, for instance, for flexible electronic display and for scientific research of the assembly of the bipolar Janus particles under electrical field (Crowley et al. 2002; Hossan et al. 2015). Therefore, it is desirable to develop a new method which can generate bipolar Janus droplets with opposite surface charges on their two hemispheres.

In this paper, a new method of forming Janus oil droplets in water by aluminum oxide nanoparticles is presented. First, aluminum oxide nanoparticles were introduced to the surface of an oil droplet; the final surface area covered with the nanoparticles is controlled by the applied 
DC electrical field. The surface of Janus droplets formed by this method is composed of two parts, one is the pure oil-water interface and the other is covered with positively charged aluminum oxide nanoparticles The effects of the concentration of the nanoparticles suspension, the droplet size and the strength of electric field on the topology of Janus droplets were studied.

\section{Materials and methods}

Aluminum oxide nanoparticles (US Research Nanomaterials, Inc., Houston, TX, USA) with an average diameter of $5 \mathrm{~nm}$ were used. The zeta potential of these particles is positive from $\mathrm{pH} 2.5$ to $\mathrm{pH} 8$ (Chera et al. 2007), which means that these particles carry positive charges when contacting with deionized water. In this study, two different concentrations of alumina nanoparticle suspensions, $20 \mathrm{mg} / \mathrm{mL}$ and $50 \mathrm{mg} / \mathrm{mL}$, were used in the experiments. A three-step procedure was used to disperse the aluminum oxide nanoparticles into deionized water: a) First, $20 \mathrm{mg}$ or $50 \mathrm{mg}$ nanoparticles were added into $1 \mathrm{~mL}$ deionized water in a beaker. b) Then the nanoparticles were dispersed by placing the beaker into an ultrasonic cleaner for 8 minutes. c) Finally, $20 \mu \mathrm{L}$ ethanol was added into the nanoparticle suspension. The ethanol acts as an inducer, which can make sure enough nanoparticles are trapped at the oil-water interface (Reincke et al. 2004; Li et al. 2006).

Mineral oil was used to generate oil droplets. In order to observe the redistribution of the nanoparticles on the droplet in response to the applied electrical field, it is desirable to avoid the unwanted effects of the droplet motion; therefore, the oil droplets were anchored onto a solid surface as sessile drops. To form a sessile oil droplet immersed in deionized water, a plastic petri dish and a piece of cover glass slide were used, and the procedures are as follows: a) Pour deionized water into the petri dish and make the water level is around $5 \mathrm{~mm}$ from the bottom; b) Put the cover glass slide on the surface of water, due the surface tension, the cover glass slide will float on water surface without sinking; c) Deposit a drop of the mineral oil on the floating cover glass slide; d) Push the glass slide into water. As the oil droplet has already attached on the surface of the glass, it will not detach and float; a sessile drop of oil in water is formed in this way. As shown in Figure 1, the contact angle of water of the sessile oil droplet system is $45^{\circ}$ (on the water side) and remains unchanged before and after applying electric field, which was 
measured with a side view microscope (Nikon, SMZ800). The size of the droplet can be adjusted by changing the volume of mineral oil.

The experimental system used in this study is shown in Figure 2. It consists of a microscope and image system, a DC power supply and a petri dish. In the experiment, the petri dish which holds deionized water and oil droplet was fixed on the stage of the microscope (Ti-E, Nikon, Japan). The DC power supplier (CSI12001X, Circuit Specialist Inc., USA) was used to apply the electrical field via the electrodes. The Nikon Ti-E microscope was used to monitor the redistribution of nanoparticles on oil droplets. The images were captured by a digital camera (DS-Qi1Mc ,Nikon) and sent to a computer to be displayed and saved.

Once the oil droplet is formed in water, as described above, the aluminum oxide nanoparticles are deposited onto the droplet surface by releasing a certain amount of the nanoparticle suspension over it by using a digital micro-pipette. As the aluminum oxide nanoparticles carry positive charges, they will adhere at the negatively charged oil-water interface, forming a uniform coverage on the droplet surface. However, due to the inter-particle cohesion forces, the nanoparticles aggregate and form small clusters uniformly distributed over the oil droplet surface. When a DC electric field is applied to the droplet, the positively charged particles on the droplet surface will be forced to move and accumulate to one side of the oil droplet. A Janus droplet partially covered with aluminum oxide nanoparticles is formed in this way. The total amount of nanoparticles adhering on the oil droplet surface can be adjusted by varying the concentration of the nanoparticle suspension. All of the experiments in this study were conducted at room temperature $\left(23-25^{\circ} \mathrm{C}\right)$.

\section{Results and discussion}

\subsection{Micro-sized and macro-sized Janus droplets}

By using the method described above, micro-sized Janus droplets and macro-sized Janus droplets can be made. An example of a micro-sized Janus droplet and an example of a macro-sized Janus droplet are shown in Figure 3 and Figure 4, respectively. For the micro-sized droplet shown in Figure 3 , it has a diameter of $67 \mu \mathrm{m}$ and was covered with the nanoparticles by depositing $2.5 \mu \mathrm{L}$ nanoparticle suspension with a concentration of $20 \mathrm{mg} / \mathrm{mL}$ over it. As shown in Figure 3(a), 
before applying electric field, the nanoparticles on the surface of the droplet were uniformly distributed. Then an electric field $(\mathrm{E}=15 \mathrm{~V} / \mathrm{cm})$ was applied from left to right. Under the applied electric field, the positively charged nanoparticles moved along the direction of the electric field and accumulated to the right side of the oil droplet. The area with accumulated nanoparticles becomes constant after 30 seconds. A Janus droplet which was partially covered with nanoparticles was formed (Figure 3(b)). The position of the accumulation region of the nanoparticles depends on the direction of the electric field. As shown in Figure 3(c), when the electric field was reversed, i.e., from right to left, the nanoparticles moved and accumulated to the left hemisphere of the oil droplet, reaching the final state as shown in Figure 3(c).

The same phenomenon can also be observed for the macro-sized Janus droplets. Figure 4 shows a droplet with a diameter of $1.1 \mathrm{~mm}$. In this case, $12.5 \mu \mathrm{L} 50 \mathrm{mg} / \mathrm{mL}$ nanoparticle suspension was deposited over 5 times near the top of the droplet to make sure enough nanoparticles adhered on the droplet. As seen from Figure 4(a), initially the particles distribute uniformly over the drop surface. Then an electric field of $25 \mathrm{~V} / \mathrm{cm}$ was applied from left to right, the nanoparticles moved towards right and eventually reached a final state after 2 minutes (Figure 4(b)). Similarly, under the reversed electric field, the nanoparticles moved in the opposite direction and accumulated to the left hemisphere of the oil droplet (Figure 4(c)).

The comparison of Figure 3 and 4 clearly shows that the motion and accumulation of the nanoparticles in response to the applied electrical field is the same for both micro-sized droplets and macro-sized droplets. However, it's relatively difficult to generate micro-sized droplets with accurately controlled size. Furthermore, it is difficult to introduce the same amount of nanoparticles onto the surface of smaller micro-sized droplets. Therefore, macro-sized droplets were used to carry out the studies of the effects of the concentration of the nanoparticle suspension, the electric field and the size of the droplets on the topology of Janus droplets.

\subsection{Effect of the concentration of the nanoparticle suspension}

To study the effect of the concentration of the nanoparticle suspension on the topology of Janus droplets, aluminum oxide nanoparticle suspensions with different concentrations, $20 \mathrm{mg} / \mathrm{mL}$ and $50 \mathrm{mg} / \mathrm{mL}$, were used to cover the oil droplets, respectively. In these experiments, the diameter of 
the oil droplets $(d=1.1 \mathrm{~mm})$ and the applied electric field $(E=25 \mathrm{~V} / \mathrm{cm}$, from left to right $)$ were kept constant.

When the concentration of the suspension is $20 \mathrm{mg} / \mathrm{mL}$, the redistribution of the positively charged aluminum nanoparticles under applied electric field is shown in Figure 5, as an example. Before the electric field was applied, $\mathrm{t}=0$, the nanoparticles on the surface of the oil droplet are distributed uniformly and motionless with the nanoparticle surface coverage ratio $\mathrm{r}=100 \%$, as shown in Figure 5(a). After the electric field was applied from left to right, the positively charged particles moved in the same direction as that of the electric field and the coverage ratio decreases from $100 \%$ to $20.75 \%$ as time went by (Figure $5(\mathrm{~b}) \sim(e)$ ). At the final state, all of the nanoparticles accumulated in a small area on the right side of the droplet, leaving a large "blank" oil-water interface behind, and a Janus droplet with $\mathrm{r}=20.75 \%$ was formed finally, as shown in Figure 5(f). The sequence of images in Figure 6 shows an example of the redistribution of nanoparticles on the oil droplet when the concentration of the nanoparticle suspension is $50 \mathrm{mg} / \mathrm{mL}$. The similar phenomenon can be observed from the images in Figure 6 . That is, the original uniformly-distributed nanoparticles moved and accumulated to the right side of the oil droplet in response to the externally applied electric field. The comparison of Figure 5(f) with Figure 6(f) indicates that when the concentration increases from $20 \mathrm{mg} / \mathrm{mL}$ to $50 \mathrm{mg} / \mathrm{mL}$, at the finial state, the nanoparticle coverage ratio $r$ increases significantly from $20.75 \%$ to $50 \%$. As the increase of the concentration of the nanoparticle suspension, the total amount of the nanoparticles adhering on the surface of the oil droplet increases. This can be seen by comparing the original states of the oil droplets as shown in Figure 5(a) and Figure 6(a). Obviously, the more nanoparticles at the oil-water interface, the larger the final accumulation area. Therefore, the following conclusion can be drawn: the surface area of the Janus droplet that is covered with nanoparticles enlarges with the increase of the concentration of the nanoparticle suspension. Under this set of specific conditions, when the concentration of the nanoparticle suspension is $50 \mathrm{mg} / \mathrm{mL}$, a Janus droplet whose whole right hemisphere is covered with aluminum nanoparticles $(\mathrm{r}=50 \%)$ can be obtained.

\subsection{Effect of the applied electric field}

The strength of the externally applied electric field is another factor that will affect the topology of Janus droplets. The effect of the applied electric field on the redistribution of nanoparticles on 
the surface of the oil droplet can be understood as follows. Under externally applied electrical field, the positively charged nanoparticles will be pushed by the external electrical field force and move to the side of the oil droplet facing the negative electrode. Once the nanoparticles get closer, they start to repel each other due to the electrostatic repulsive force between the particles. At final state, the two forces acting on the particles will be balanced, and the nanoparticles are confined in an area. When the external electric field changes, the electrical field force will change, hence affect the balance with the electrostatic repulsive force between the nanoparticles, and consequently, the distance between the nanoparticles. Therefore, the final accumulation area of the nanoparticles changes with the applied electrical field.

Figure 7 and Figure 8 shows the redistribution processes of the alumina nanoparticles on the surface of the oil droplet of $1.1 \mathrm{~mm}$ in diameter under different electric field, $15 \mathrm{~V} / \mathrm{cm}$ and $35 \mathrm{~V} / \mathrm{cm}$, respectively. It is clearly shown in these figures that, at the final state, the nanoparticle coverage ratio $\mathrm{r}$ decreases from $43.17 \%$ to $17.16 \%$ when the electric field increases from $15 \mathrm{~V} / \mathrm{cm}$ to $35 \mathrm{~V} / \mathrm{cm}$, which means the final accumulation area of the nanoparticles becomes smaller as the externally applied electric field increases. Recall that Figure 5 shows the redistribution processes of the alumina nanoparticles on the surface of the same sized oil droplet under $25 \mathrm{~V} / \mathrm{cm}$. By comparing Figures 5, 7 and 8, the following can be concluded:

(1) The final surface coverage of Janus droplets by the nanoparticles decreases with the applied electric field, e.g., $43.17 \%$ for $15 \mathrm{~V} / \mathrm{cm}, 20.75 \%$ for $25 \mathrm{~V} / \mathrm{cm}$ and $17.16 \%$ for $35 \mathrm{~V} / \mathrm{cm}$.

(2) For an oil droplet with a fixed size and the same amount of nanoparticles covered on its surface, the particles move faster and the time required to reach the final state is shorter if the applied electrical field is stronger. For example, when $\mathrm{E}=15 \mathrm{~V} / \mathrm{cm}$, it takes more than 6 mins for the nanoparticles to reach the final state (Figure 7). While it takes around 2 mins under $\mathrm{E}=35 \mathrm{~V} / \mathrm{cm}($ Figure 8$)$.

\subsection{Effect of oil droplet size}

When a uniform electric field is applied to an oil droplet through an electrolyte solution, in a spherical coordinate system, the local electrical potential along the oil droplet surface $(\phi(\theta))$ can be obtained as (Zhang and Li 2013): 


$$
\phi(\theta)=\frac{-3 \varepsilon_{m}}{\varepsilon_{d}+2 \varepsilon_{m}} E_{\infty} a \cos \theta
$$

where $\varepsilon_{m}$ and $\varepsilon_{d}$ are the relative dielectric constants of the electrolyte solution and the oil droplet $\left(\varepsilon_{m}=80, \varepsilon_{d}=2.5\right)$, respectively. $E_{\infty}$ is the electric field far from the oil droplet, $a$ is the radius of the droplet. With this equation, the local electric field along the surface of the oil droplet $(E(\theta))$ can be calculated by:

$$
E(\theta)=\nabla \phi(\theta)=\frac{3 \varepsilon_{m}}{\varepsilon_{d}+2 \varepsilon_{m}} E_{\infty} a \sin \theta
$$

Clearly, the local electric field along the oil droplet surface is dependent on the droplet size. For a given externally applied electric field, $E_{\infty}$, the larger the droplet size, the higher the local electric field along its surface, which will generate relatively large electrical driving force on the nanoparticles to push the particles to move towards one end of the droplet. Therefore, when the other parameters are fixed, the relative accumulation area (the nanoparticle accumulation surface area over the whole surface area of the oil droplet) decreases with the increase of the size of the oil droplet.

To study the effect of the droplet size on the topology of Janus droplets, oil droplets with different sizes, $1.9 \mathrm{~mm}$ and $3.1 \mathrm{~mm}$ in diameter, in addition to $1.1 \mathrm{~mm}$ in diameter (Figure 6), were formed, respectively. Under a fixed electric field, $\mathrm{E}=25 \mathrm{~V} / \mathrm{cm}$, and a fixed concentration of nanoparticle suspension, $\mathrm{C}=50 \mathrm{mg} / \mathrm{mL}$, the redistribution of nanoparticles on different size droplets has been studied. Figure 9 shows the redistribution of particles on the surface of an oil droplet of $1.9 \mathrm{~mm}$ in diameter. It is clearly shown from the sequences of images in this figure that the nanoparticles moved and accumulated to the right pole of the oil droplet with the nanoparticle surface coverage ratio $\mathrm{r}=38.91 \%$ at the finial state. The redistribution and accumulation of the nanoparticles on the surface of an oil droplet of $3.1 \mathrm{~mm}$ in diameter is shown in Figure 10, and the nanoparticle surface coverage ratio is $32.06 \%$ at the final state. The comparison of the final nanoparticle coverage on oil droplets with different sizes, as shown in Figure 6(f), Figure 9(f) and Figure 10(f), indicates that the nanoparticle coverage decreases gradually with the increase of the size of the oil droplets under a given externally applied electric field $25 \mathrm{~V} / \mathrm{cm}$ from $\mathrm{r}=50 \%$, to $38.91 \%$ and to $32.06 \%$ for oil droplets with a diameter of $1.1 \mathrm{~mm}$, 
$1.9 \mathrm{~mm}$ and $3.1 \mathrm{~mm}$, respectively. This confirms the above theoretical analysis that the relative accumulation area decreases with the increase of the size of the oil droplet.

All of the experiments shown in the above sections were repeated at least 3 times, and the comparisons of the experimental results obtained under the same conditions prove the reliability of this method. For example, when $12.5 \mu \mathrm{L} 50 \mathrm{mg} / \mathrm{mL}$ nanoparticle suspension was used to cover oil droplets with a diameter of $1.1 \mathrm{~mm}$, the Janus droplets with $50 \%$ nanoparticle coverage can always be generated under externally applied electric field of $25 \mathrm{~V} / \mathrm{cm}$, as shown in Figure 4(b) and Figure 6(f).

\section{Conclusion}

This paper presents a new method to generate Janus droplets (i.e., an oil droplet coated partially with aluminum oxide nanoparticles) by applying DC electric field. Both the micro-sized and macro-sized Janus droplets can be produced by this approach. The final surface area that is covered by the nanoparticles varies with the concentration of the nanoparticles suspension, the applied electric field as well as the oil droplet size. Generally, a higher concentration of nanoparticle suspension will result in a Janus droplet with a larger particle accumulation area. Increase in droplet size and the applied electric field concentrates the charged particles in a smaller area on the Janus droplets.

\section{Acknowledgement}

The authors wish to thank the financial support of the Natural Sciences and Engineering Research Council (NSERC) of Canada through a research grant to D. Li. 


\section{References}

Ahn S, Kim DW, Kim YW, Yoo JY (2010) Generation of janus droplets for enhanced mixing in microfluidics. Int J Precis Eng Manuf 11:799-802. doi: 10.1007/s12541-010-0095-Z

Amah E, Shah K, Fischer I, Singh P (2016) Electrohydrodynamic manipulation of particles adsorbed on the surface of a drop. Soft Matter 12:1663-1673. doi: 10.1039/C5SM02195B

Bickel T, Majee A, Würger A (2013) Flow pattern in the vicinity of self-propelling hot Janus particles. Phys Rev E 88:012301. doi: 10.1103/PhysRevE.88.012301

Binks BP, Fletcher PDI (2001) Particles adsorbed at the oil-water interface: A theoretical comparison between spheres of uniform wettability and "Janus" particles. Langmuir 17:4708-4710. doi: $10.1021 / \mathrm{la} 0103315$

Bormashenko E, Bormashenko Y, Pogreb R, Gendelman O (2011) Janus Droplets: Liquid Marbles Coated with Dielectric/Semiconductor Particles. Langmuir 27:7-10. doi: 10.1021/la103653p

Chera L, Palcevskis E, Berzins M, et al (2007) Dispersion of nanosized ceramic powders in aqueous suspensions. J Phys Conf Ser 93:012010. doi: 10.1088/1742-6596/93/1/012010

Chevalier Y, Bolzinger MA (2013) Emulsions stabilized with solid nanoparticles: Pickering emulsions. Colloids Surfaces A Physicochem Eng Asp 439:23-34. doi: 10.1016/j.colsurfa.2013.02.054

Crowley JM, Sheridon NK, Romano L (2002) Dipole moments of gyricon balls. J Electrostat 55:247-259. doi: 10.1016/S0304-3886(01)00208-X

Daghighi Y, Gao Y, Li D (2011) 3D numerical study of induced-charge electrokinetic motion of heterogeneous particle in a microchannel. Electrochim Acta 56:4254-4262. doi: 10.1016/j.electacta.2011.01.083

Daghighi Y, Li D (2011) Micro-valve using induced-charge electrokinetic motion of Janus particle. Lab Chip 11:2929-2940. doi: 10.1039/c1lc20229d

Dommersnes P, Rozynek Z, Mikkelsen A, et al (2013) Active structuring of colloidal armour on liquid drops. Nat Commun 4:2066. doi: 10.1038/ncomms3066

Edel JB, Kornyshev AA, Urbakh M (2013) Self-assembly of nanoparticle arrays for use as mirrors, sensors, and antennas. ACS Nano 7:9526-9532. doi: 10.1021/nn405712r

Fattah Z, Loget G, Lapeyre V, et al (2011) Straightforward single-step generation of microswimmers by bipolar electrochemistry. Electrochim Acta 56:10562-10566. doi: 10.1016/j.electacta.2011.01.048

Friberg SE, Kovach I, Koetz J (2013) Equilibrium topology and partial inversion of janus drops: A numerical analysis. ChemPhysChem 14:3772-3776. doi: 10.1002/cphc.201300635

Ge L, Shao W, Lu S, Guo R (2014) Droplet topology control of Janus emulsion prepared in one-step high energy mixing. Soft Matter 10:4498-4505. doi: 10.1039/c4sm00456f 
Glaser N, Adams DJ, Böker A, Krausch G (2006) Janus particles at liquid-liquid interfaces. Langmuir 22:5227-5229. doi: 10.1021/la060693i

Guzowski J, Korczyk PM, Jakiela S, Garstecki P (2012) The structure and stability of multiple microdroplets. Soft Matter 8:7269-7278. doi: 10.1039/c2sm25838b

Hasinovic H, Friberg SE (2011) One-step inversion process to a Janus emulsion with two mutually insoluble oils. Langmuir 27:6584-6588. doi: 10.1021/la105118h

Hasinovic H, Friberg SE, Rong G (2011) A one-step process to a Janus emulsion. J Colloid Interface Sci 354:424-426. doi: 10.1016/j.jcis.2010.10.004

Hossan MR, Gopmandal PP, Dillon R, Dutta P (2015) Bipolar janus particle assembly in microdevice. Electrophoresis 36:722-730. doi: 10.1002/elps.201400423

Jeong J, Gross A, Wei WS, et al (2015) Liquid crystal Janus emulsion droplets: preparation, tumbling, and swimming. Soft Matter 11:6747-6754. doi: 10.1039/C5SM01053E

Jiang HR, Yoshinaga N, Sano M (2010) Active Motion of a Janus Particle by Self-Thermophoresis in a Defocused Laser Beam. Phys Rev Lett 105:268302. doi: 10.1103/PhysRevLett.105.268302

Levine S, Bowen BD, Partridge SJ (1989) Stabilization of emulsions by fine particles I. Partitioning of particles between continuous phase and oil/water interface. Colloids and Surfaces 38:325-343. doi: 10.1016/0166-6622(89)80271-9

Li YJ, Huang WJ, Sun SG (2006) A universal approach for the self-assembly of hydrophilic nanoparticles into ordered monolayer films at a toluene/water interface. Angew Chemie - Int Ed 45:2537-2539. doi: 10.1002/anie.200504595

Loget G, Lapeyre V, Garrigue P, et al (2011) Versatile procedure for synthesis of janus-type carbon tubes. Chem Mater 23:2595-2599. doi: 10.1021/cm2001573

Loget G, Roche J, Gianessi E, et al (2012a) Indirect bipolar electrodeposition. J Am Chem Soc 134:20033-20036. doi: 10.1021/ja310400f

Loget G, Roche J, Kuhn A (2012b) True bulk synthesis of Janus objects by bipolar electrochemistry. Adv Mater 24:5111-5116. doi: 10.1002/adma.201201623

Lone S, Cheong IW (2014) Fabrication of polymeric Janus particles by droplet microfluidics. RSC Adv 4:13322-13333. doi: 10.1039/c4ra00158c

Luo M, Olivier GK, Frechette J (2012) Electrostatic interactions to modulate the reflective assembly of nanoparticles at the oil-water interface. Soft Matter 11923-11932. doi: 10.1039/c2sm26890f

Nie Z, Li W, Seo M, et al (2006) Janus and ternary particles generated by microfluidic synthesis: Design, synthesis, and self-assembly. J Am Chem Soc 128:9408-9412. doi: 10.1021/ja060882n 
Nisisako T, Torii T (2007) Formation of biphasic janus droplets in a microfabricated channel for the synthesis of shape-controlled polymer microparticles. Adv Mater 19:1489-1493. doi: 10.1002/adma.200700272

Nisisako T, Torii T, Takahashi T, Takizawa Y (2006) Synthesis of Monodisperse Bicolored Janus Particles with Electrical Anisotropy Using a Microfluidic Co-Flow System. Adv Mater 18:11521156. doi: 10.1002/adma.200502431

Nonomura Y, Komura S, Tsujii K (2004) Adsorption of disk-shaped Janus beads at liquid-liquid interfaces. Langmuir 20:11821-11823. doi: 10.1021/la0480540

Ongaro M, Gambirasi A, Favaro M, et al (2014) Asymmetrical modification of carbon microfibers by bipolar electrochemistry in acetonitrile. Electrochim Acta 116:421-428. doi: 10.1016/j.electacta.2013.11.066

Ouriemi M, Vlahovska PM (2015) Electrohydrodynamic Deformation and Rotation of a Particle-Coated Drop. Langmuir 31:6298-6305. doi: 10.1021/acs.langmuir.5b00774

Pannacci N, Bruus H, Bartolo D, et al (2008) Equilibrium and Nonequilibrium States in Microfluidic Double Emulsions. Phys Rev Lett 101:164502. doi: 10.1103/PhysRevLett.101.164502

Reincke F, Hickey SG, Kegel WK, Vanmaekelbergh D (2004) Spontaneous Assembly of a Monolayer of Charged Gold Nanocrystals at the Water/Oil Interface. Angew Chemie - Int Ed 43:458-462. doi: 10.1002/anie.200352339

Roh KH, Martin DC, Lahann J (2005) Biphasic Janus particles with nanoscale anisotropy. Nat Mater 4:759-763. doi: 10.1038/nmat1486

Rozynek Z, Dommersnes P, Mikkelsen a., et al (2014a) Electrohydrodynamic controlled assembly and fracturing of thin colloidal particle films confined at drop interfaces. Eur Phys J Spec Top 223:1859-1867. doi: 10.1140/epjst/e2014-02231-x

Rozynek Z, Mikkelsen A, Dommersnes P, Fossum JO (2014b) Electroformation of Janus and patchy capsules. Nat Commun 5:3945. doi: 10.1038/ncomms4945

Schaming D, Hojeij M, Younan N, et al (2011) Photocurrents at polarized liquid|liquid interfaces enhanced by a gold nanoparticle film. Phys Chem Chem Phys 13:17704-17711. doi: $10.1039 / \mathrm{c} 1 \mathrm{cp} 22072 \mathrm{a}$

Shardt O, Derksen JJ, Mitra SK (2014) Simulations of Janus droplets at equilibrium and in shear. Phys Fluids 26:012104. doi: 10.1063/1.4861717

Shklyaev S (2015) Janus droplet as a catalytic micromotor. EPL (Europhysics Letters) 110:54002.

Sopha H, Roche J, Svancara I, Kuhn A (2014) Wireless electrosampling of heavy metals for stripping analysis with bismuth-based janus particles. Anal Chem 86:10515-10519. doi: 10.1021/ac5033897

Torza S, Mason SG (1970) Three-phase interactions in shear and electrical fields. J Colloid Interface Sci 33:67-83. doi: 10.1016/0021-9797(70)90073-1 
Utada AS, Lorenceau E, Link DR, et al (2005) Monodisperse Double Emulsions Generated from a Microcapillary Device. Science 308:537-541. doi: 10.1126/science.1109164

Walther A, Müller AH (2008) Janus particles. Soft Matter 4:663-668. doi: 10.1039/b718131k

Wang Y, Zhang C, Tang C, et al (2011) Emulsion interfacial synthesis of asymmetric janus particles. Macromolecules 44:3787-3794. doi: 10.1021/ma102945t

Wurm F, Kilbinger AFM (2009) Polymeric Janus Particles. Angew Chemie Int Ed 48:8412-8421. doi: 10.1002/anie.200901735

Xu J, Ma A, Liu T, et al (2013) Janus-like Pickering emulsions and their controllable coalescence. Chem Commun (Camb) 49:10871-3. doi: 10.1039/c3cc46738d

Yogev D, Efrima S (1991) Chemical aspects of silver metal liquid-like films. J Colloid Interface Sci 147:88-97. doi: 10.1016/0021-9797(91)90137-W

Yoon J, Lee KJ, Lahann J (2011) Multifunctional polymer particles with distinct compartments. J Mater Chem 21:8502-8510. doi: 10.1039/c1jm10673b

Zarzar LD, Sresht V, Sletten EM, et al (2015) Dynamically reconfigurable complex emulsions via tunable interfacial tensions. Nature 518:520-524. doi: 10.1038/nature14168

Zhang F, Li D (2013) Induced-charge electroosmotic flow around dielectric particles in uniform electric field. J Colloid Interface Sci 410:102-110. doi: 10.1016/j.jcis.2013.08.017 


\section{Figure Legends}

Figure 1. Side view image of a sessile oil droplet with a diameter of $1.9 \mathrm{~mm}$ on a glass surface immersed in deionized water.

Figure 2. Schematic diagram of the experimental system.

Figure 3. The formation of a micro-sized Janus oil drop with a diameter of $67 \mu \mathrm{m}$ under externally applied electric field. (a) Before the electric field was applied, the nanoparticles were distributed uniformly on the surface of the oil droplet. (b) The nanoparticles were accumulated to the right hemisphere of the oil droplet after the electric field from left to right was applied for approximately 30 seconds (c) After reversing the direction of the electric field, the nanoparticles were accumulated to the left hemisphere of the droplet. The externally applied electric field was $15 \mathrm{~V} / \mathrm{cm}$, and $2.5 \mu \mathrm{L}$ nanoparticle suspension with a concentration of $20 \mathrm{mg} / \mathrm{mL}$ was released over the oil droplet.

Figure 4. The formation of a macro-sized Janus oil drop with a diameter of $1.1 \mathrm{~mm}$ under externally applied electric field. (a) Before the electric field was applied, the nanoparticles distributed uniformly on the surface of the oil droplet. (b) The nanoparticles accumulated to the right hemisphere of the oil droplet after the electric field from left to right was applied for approximately 2 minutes. (c) After reversing the direction of the electric field, the nanoparticles accumulated to the left hemisphere. The externally applied electric field was $25 \mathrm{~V} / \mathrm{cm}$, and $12.5 \mu \mathrm{L}$ nanoparticle suspension with a concentration of $50 \mathrm{mg} / \mathrm{mL}$ was released over the oil droplet. 
Figure 5. The redistribution of aluminum oxide nanoparticles on the surface of an oil drop of 1.1 $\mathrm{mm}$ in diameter under $\mathrm{E}=25 \mathrm{~V} / \mathrm{cm}$ at different time. $12.5 \mu \mathrm{L} 20 \mathrm{mg} / \mathrm{mL}$ nanoparticle suspension was released over the oil droplet. Two minutes after applying electric field, nanoparticles reached the final state when the coverage ratio (r) remained unchanged, $r=20.75 \%$. (a) $t=0 \min , r=100 \%$; (b) $t=1 \min , r=31.96 \%$; (c) $t=2 \min , r=$ $20.75 \%$; (d) $\mathrm{t}=3 \min , \mathrm{r}=20.75 \%$; (e) $\mathrm{t}=4 \mathrm{~min}, \mathrm{r}=20.75 \%$; (f) $\mathrm{t}=5 \mathrm{~min}, \mathrm{r}=20.75 \%$.

Figure 6. The redistribution of aluminum oxide nanoparticles on the surface of an oil drop of 1.1 $\mathrm{mm}$ in diameter under $\mathrm{E}=25 \mathrm{~V} / \mathrm{cm}$ at different time. $12.5 \mu \mathrm{L} 50 \mathrm{mg} / \mathrm{mL}$ nanoparticle suspension was released over the oil droplet. Two minutes after applying the electric field, nanoparticles reached the final state when the coverage ratio remained unchanged, $r=50 \%$. (a) $t=0 \min , r=100 \%$; (b) $t=1 \min , r>50 \%$; (c) $t=2 \min , r=$ $50 \% ;(d) t=3 \min , r=50 \% ;(e) t=4 \min , r=50 \% ;(f) t=5 \min , r=50 \%$.

Figure 7. The redistribution of aluminum nanoparticles on the surface of an oil drop of $1.1 \mathrm{~mm}$ in diameter under $\mathrm{E}=15 \mathrm{~V} / \mathrm{cm}$ (from left to right) at different time. $12.5 \mu \mathrm{L} 20 \mathrm{mg} / \mathrm{mL}$ nanoparticle suspension was released over the oil droplet. When $t=6 \mathrm{~min}$, nanoparticles reached the final state with $r=28.81 \%$. (a) $t=0 \mathrm{~min}, r=100 \%$; (b) $t=$ $2 \min , r=43.12 \% ;(c) t=4 \min , r=30.05 \% ;(d) t=6 \min , r=28.81 \%$; $(e) t=8 \min , r$ $=28.81 \% ;$ (f) $\mathrm{t}=10 \mathrm{~min}, \mathrm{r}=28.81 \%$.

Figure 8. The redistribution of aluminum nanoparticles on the surface of an oil drop of $1.1 \mathrm{~mm}$ in diameter under $\mathrm{E}=35 \mathrm{~V} / \mathrm{cm}$ (from left to right) at different time. $12.5 \mu \mathrm{L} 20 \mathrm{mg} / \mathrm{mL}$ nanoparticle suspension was released over the oil droplet. When $t=3 \mathrm{~min}$, nanoparticles reached the final state with $r=17.16 \%$. (a) $t=0 \mathrm{~min}, r=100 \%$; (b) $t=$ 
$1 \min , r=31.17 \% ;(c) t=2 \min , r=17.16 \% ;(d) t=3 \min , r=17.16 \% ;(e) t=4 \min , r$ $=17.16 \% ;$ (f) $\mathrm{t}=5 \mathrm{~min}, \mathrm{r}=17.16 \%$.

Figure 9. The redistribution of aluminum nanoparticles on the surface of an oil drop of $1.9 \mathrm{~mm}$ in diameter under $\mathrm{E}=25 \mathrm{~V} / \mathrm{cm}$ (from left to right) at different time. $12.5 \mu \mathrm{L} 50 \mathrm{mg} / \mathrm{mL}$ nanoparticle suspension was released over the oil droplet. The nanoparticle coverage ratio is $38.91 \%$ at the final state. (a) $t=0 \min , r=100 \%$; (b) $t=1 \mathrm{~min}, r>50 \%$; (c) $t=$ $2 \min , r>38.91 \%$; (d) $t=3 \min , r=38.91 \%$; (e) $t=4 \min , r=38.91 \%$; $(f) t=5 \min , r=$ $38.91 \%$.

Figure 10. The redistribution of aluminum nanoparticles on the surface of an oil drop of $3.1 \mathrm{~mm}$ in diameter under $\mathrm{E}=25 \mathrm{~V} / \mathrm{cm}$ (from left to right) at different time. $12.5 \mu \mathrm{L} 50 \mathrm{mg} / \mathrm{mL}$ nanoparticle suspension was released over the oil droplet. The nanoparticle coverage ratio is $32.06 \%$ at the final state. (a) $t=0 \min , r=100 \%$; (b) $t=1 \mathrm{~min}, r>50 \%$; (c) $t=$ $2 \min , r>32.06 \%$; (d) $t=3 \min , r=32.06 \%$; (e) $t=4 \min , r=32.06 \%$; $(f) t=5 \min , r=$ $32.06 \%$. 
Figure 1

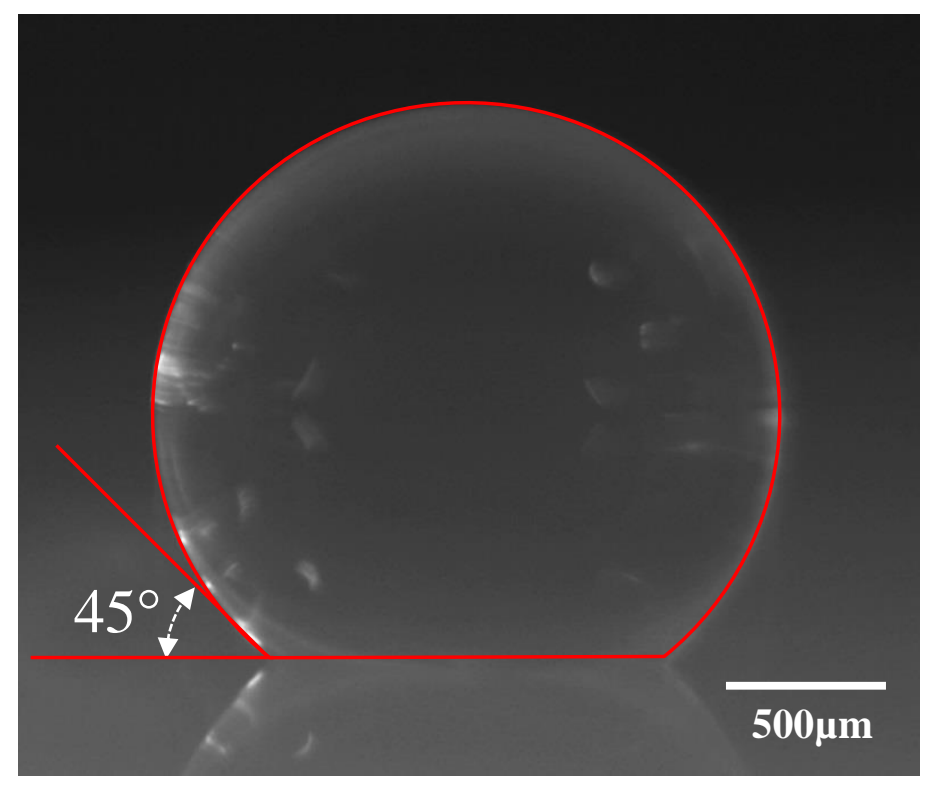


Figure 2

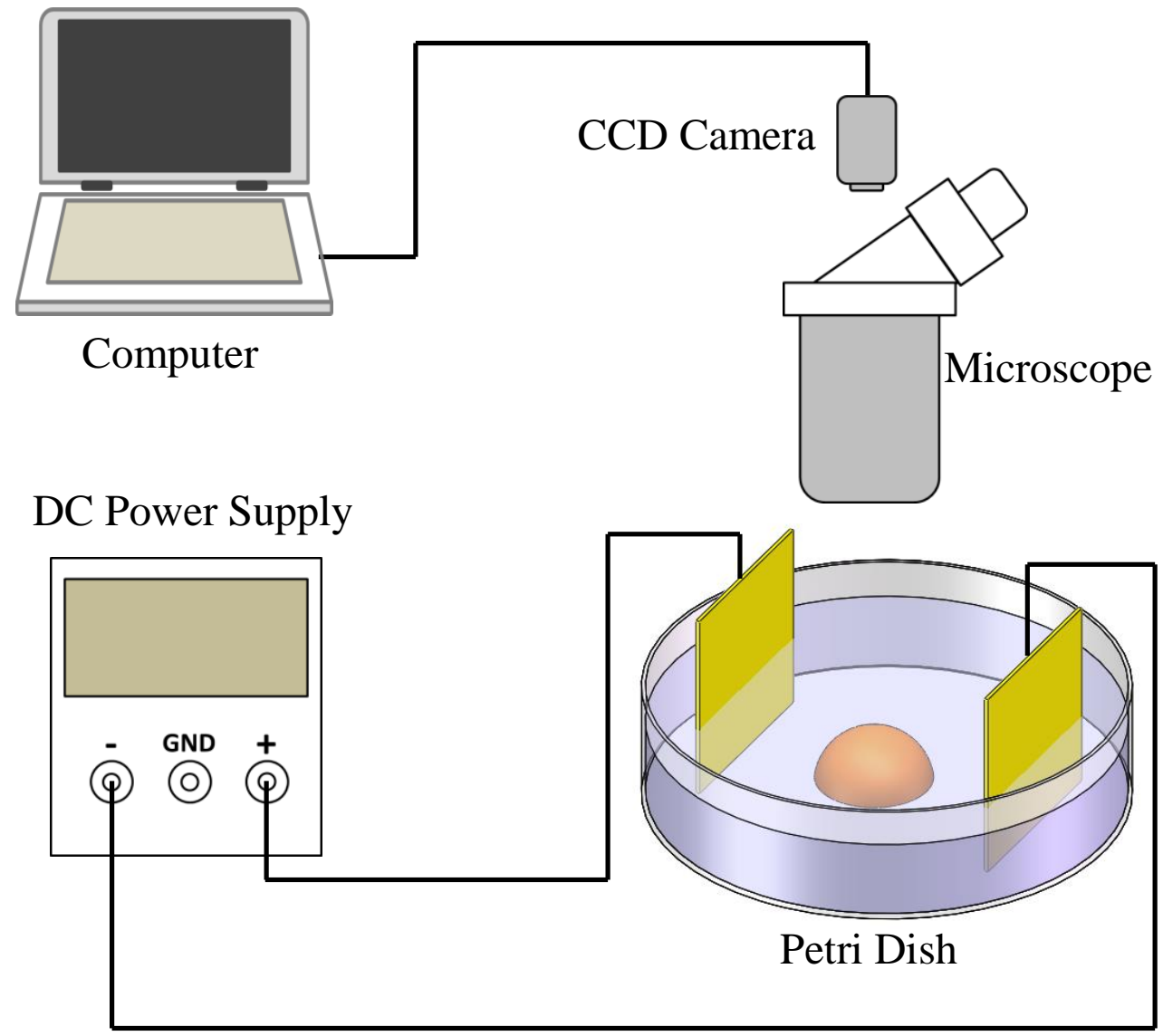


Figure 3

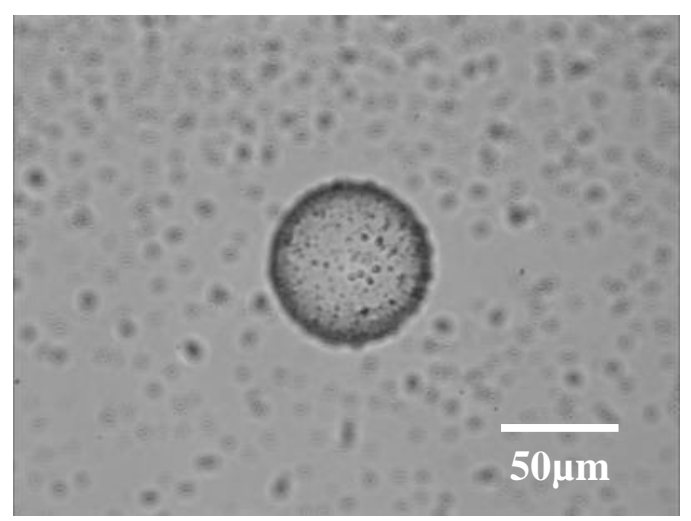

(a)

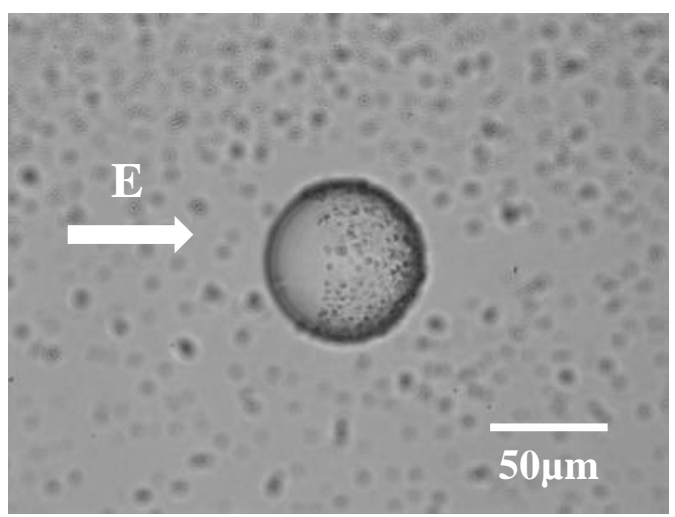

(b)

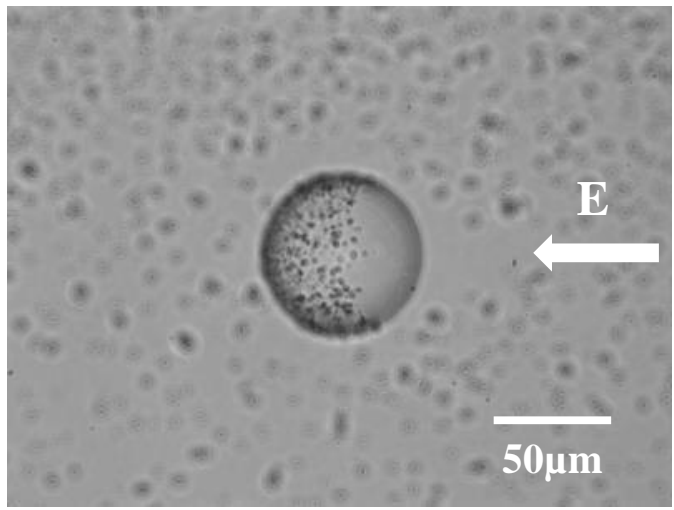

(c) 
Figure 4

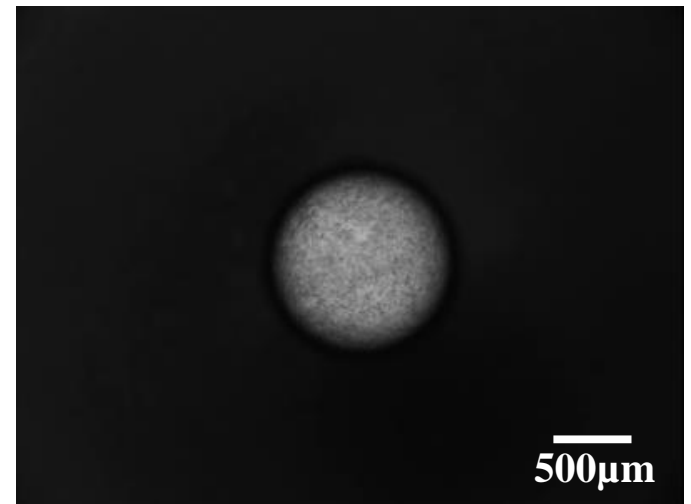

(a)

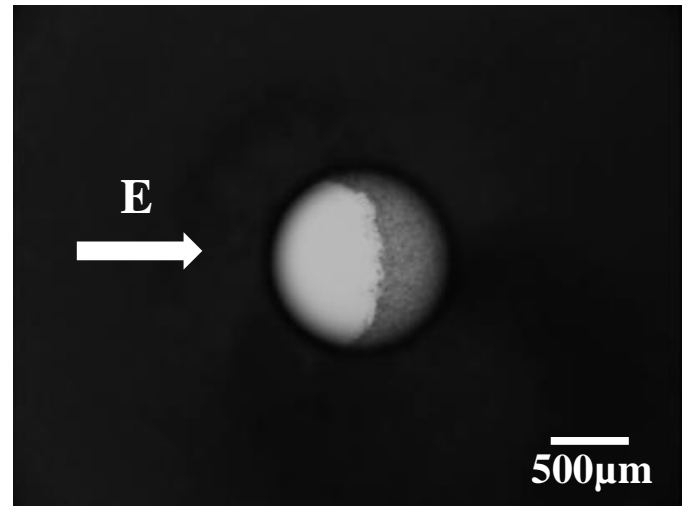

(b)

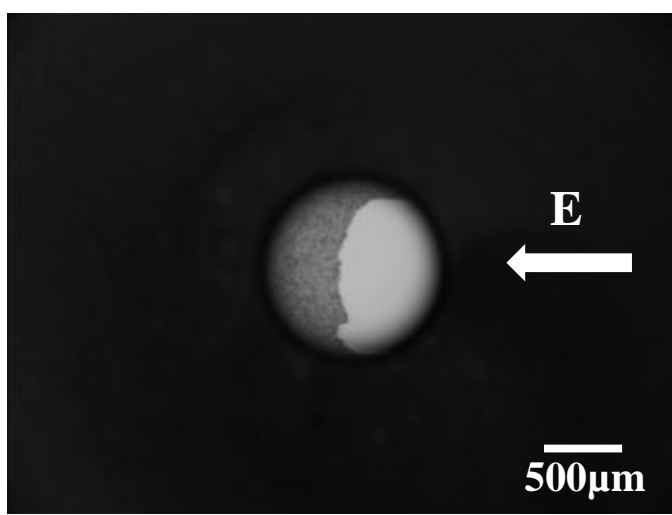

(c) 
Figure 5

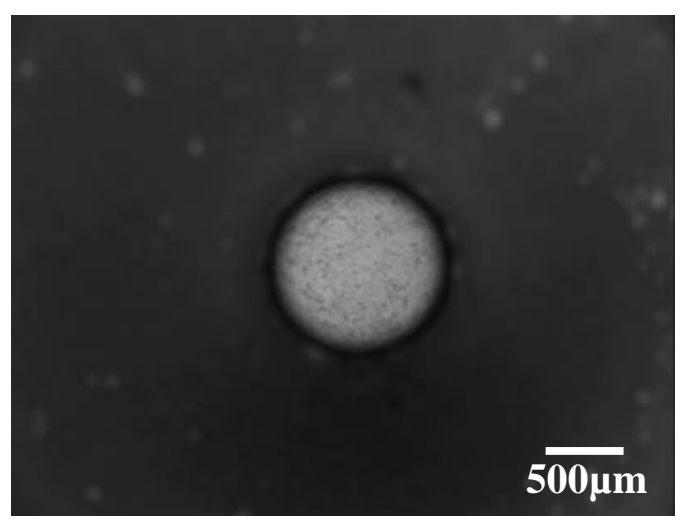

(a)

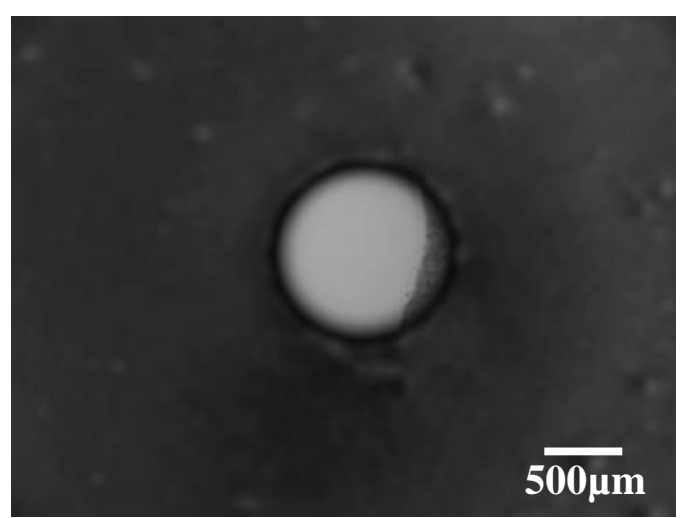

(c)

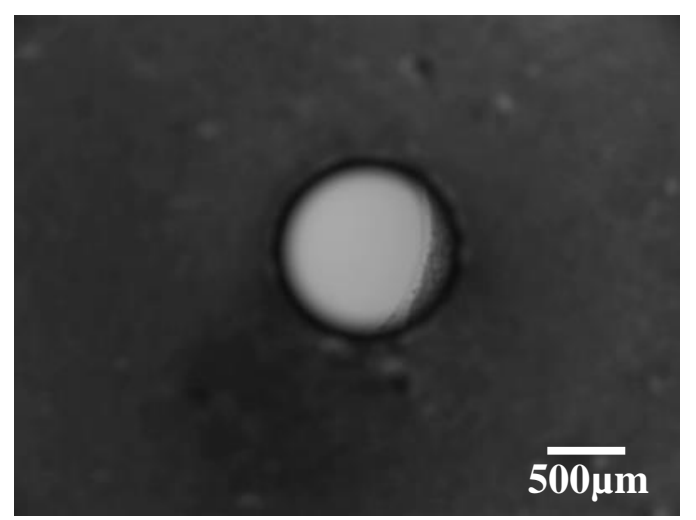

(e)

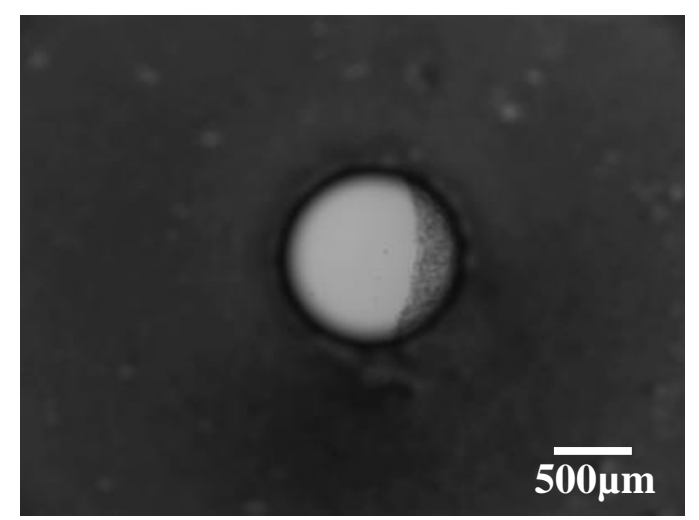

(b)

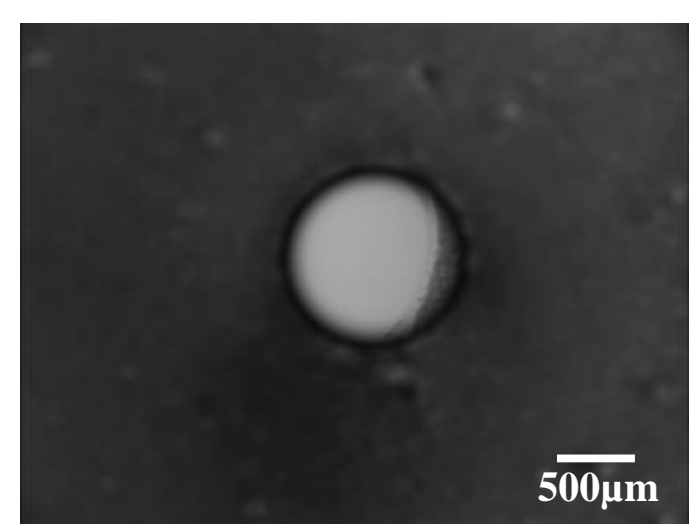

(d)

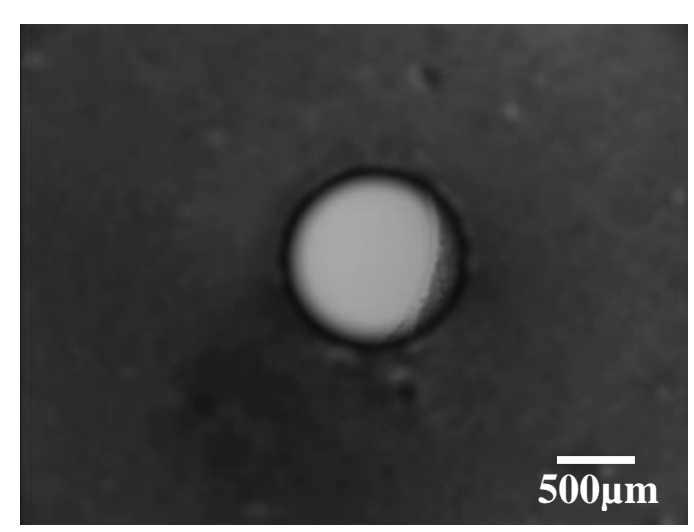

(f) 
Figure 6

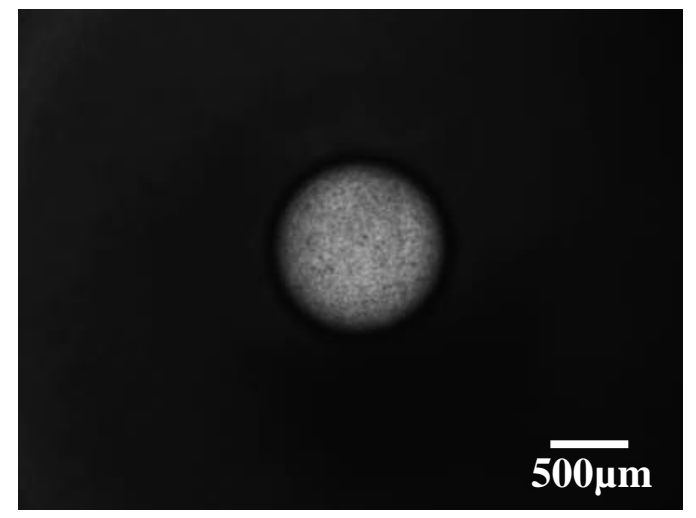

(a)

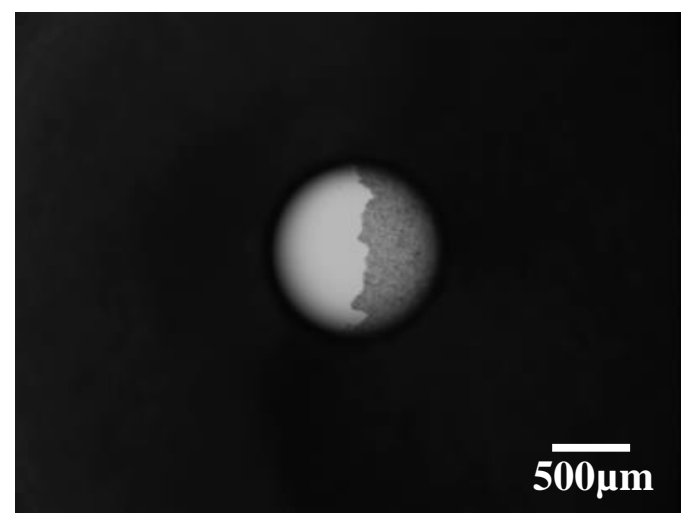

(c)

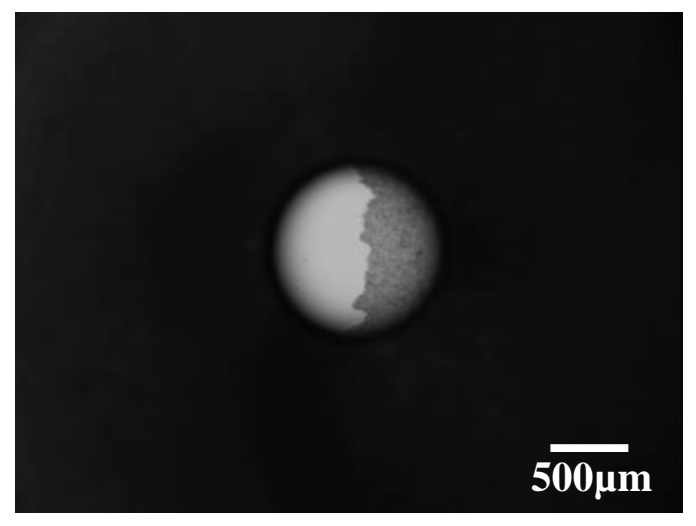

(e)

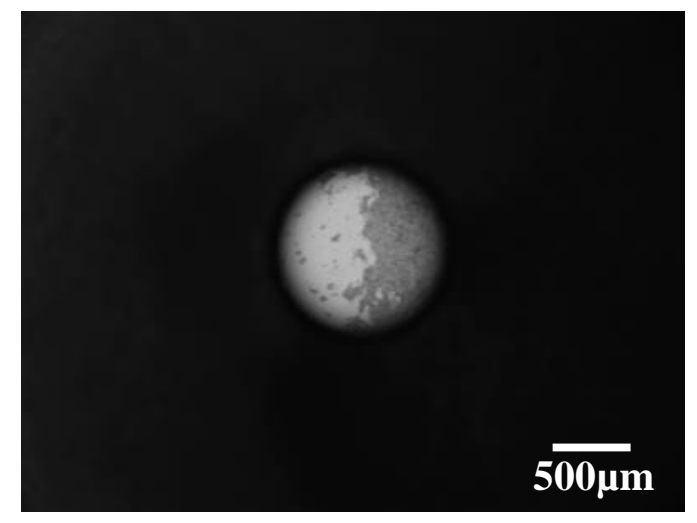

(b)

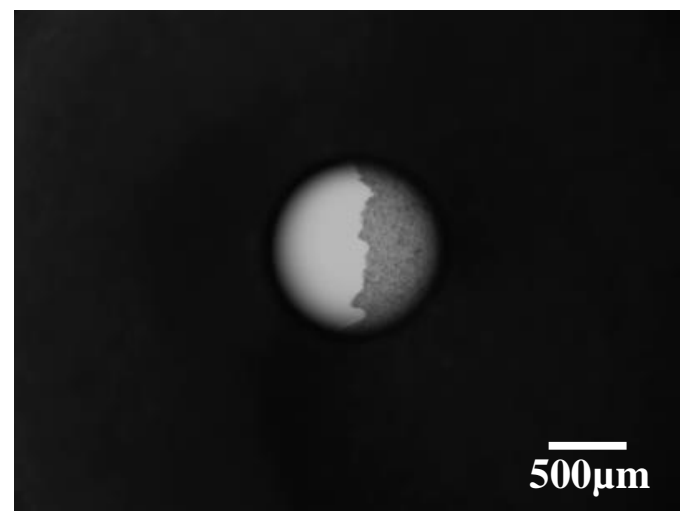

(d)

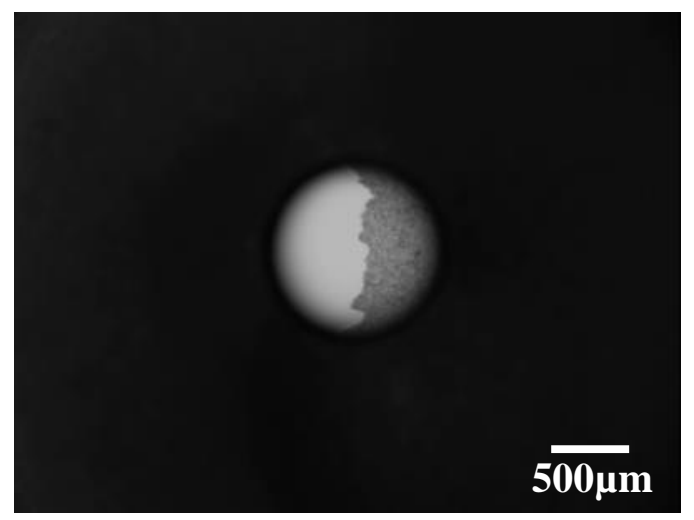

(f) 
Figure 7

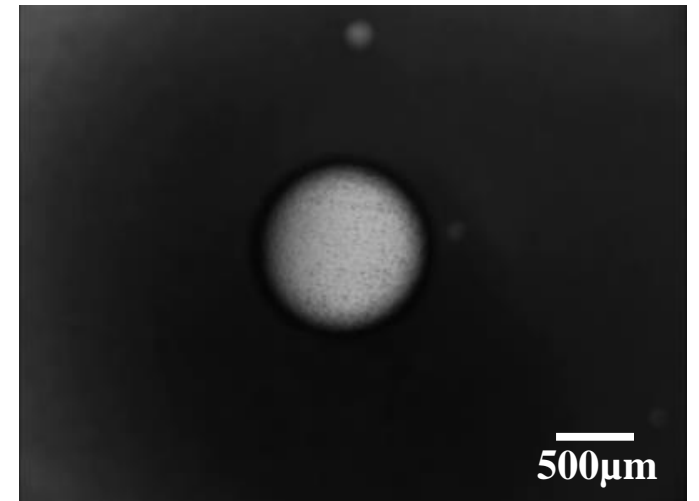

(a)

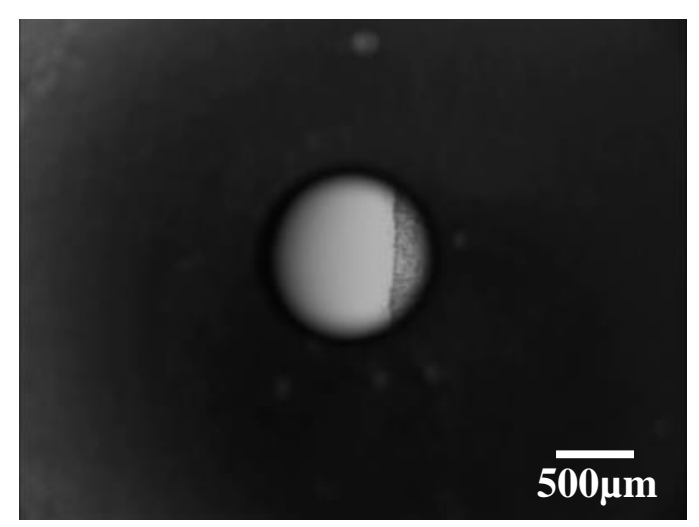

(c)

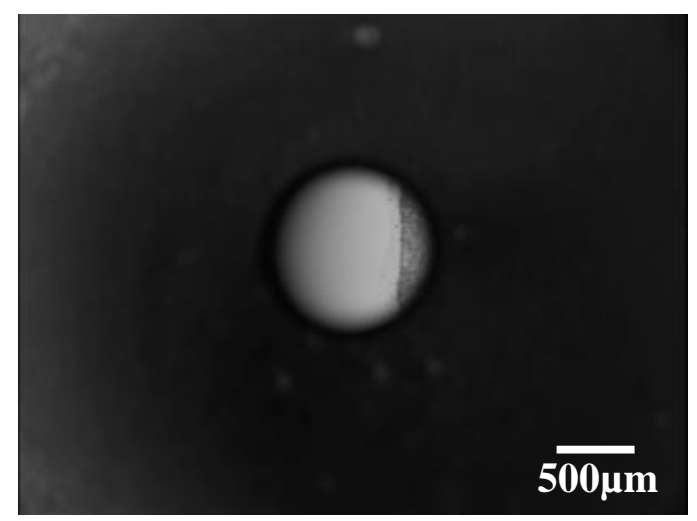

(e)

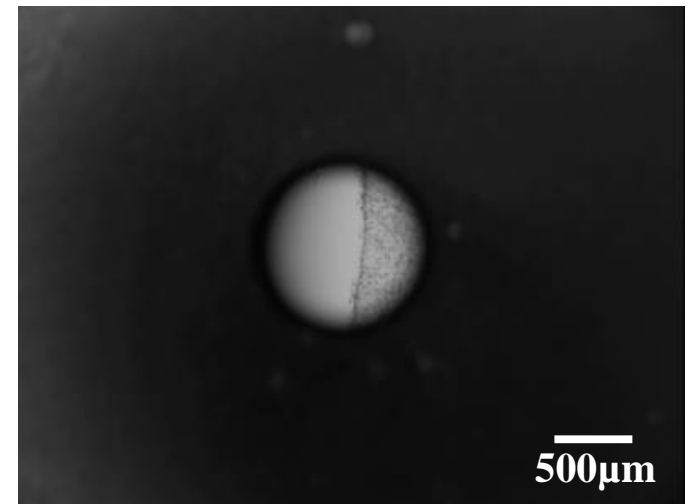

(b)

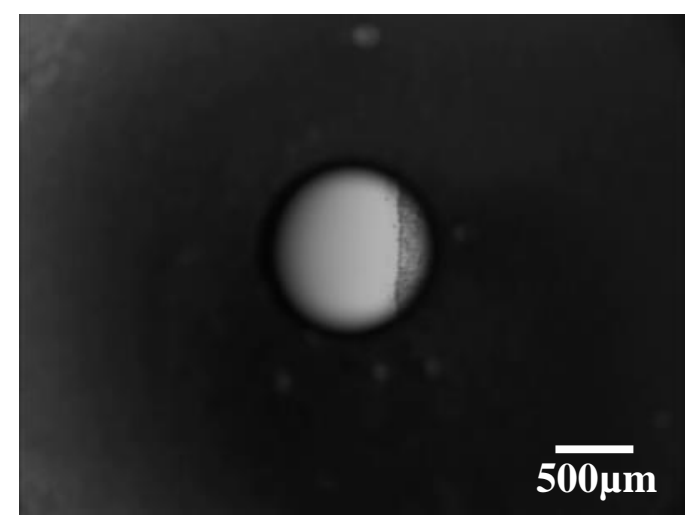

(d)

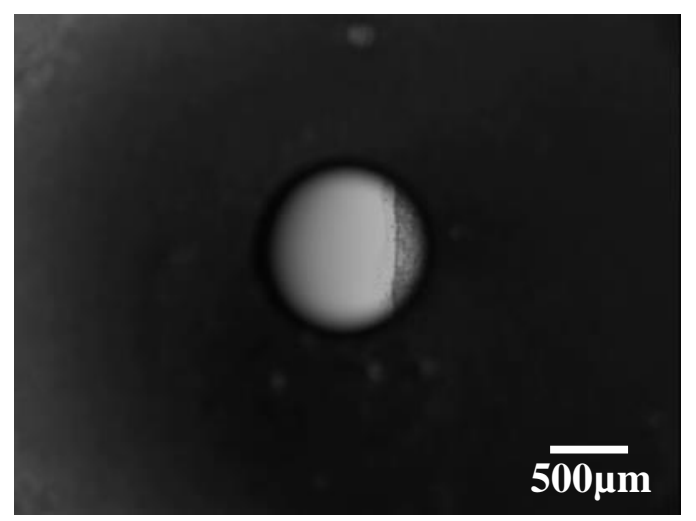

(f) 
Figure 8

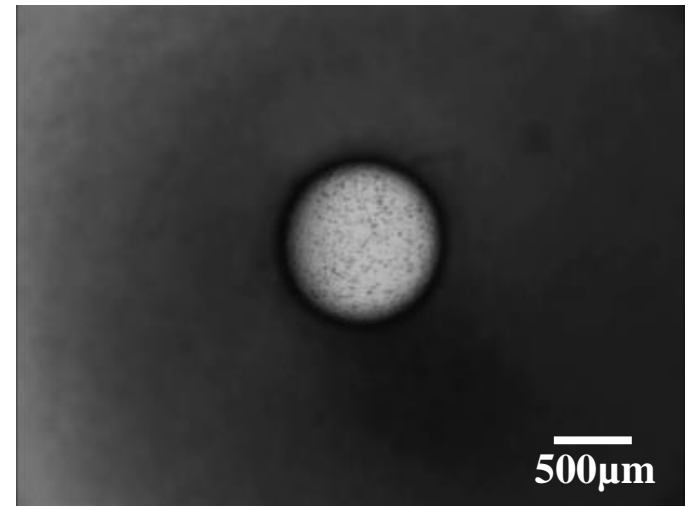

(a)

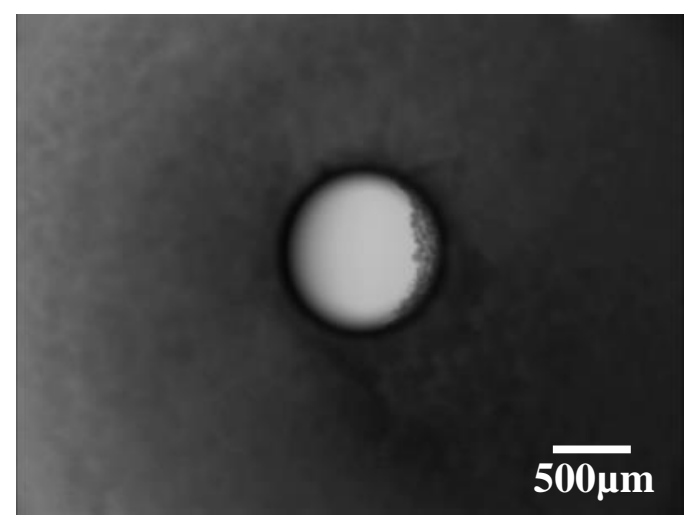

(c)

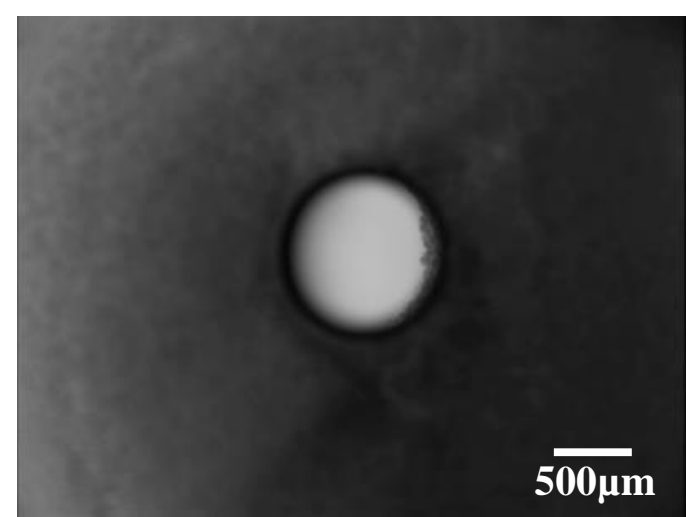

(e)

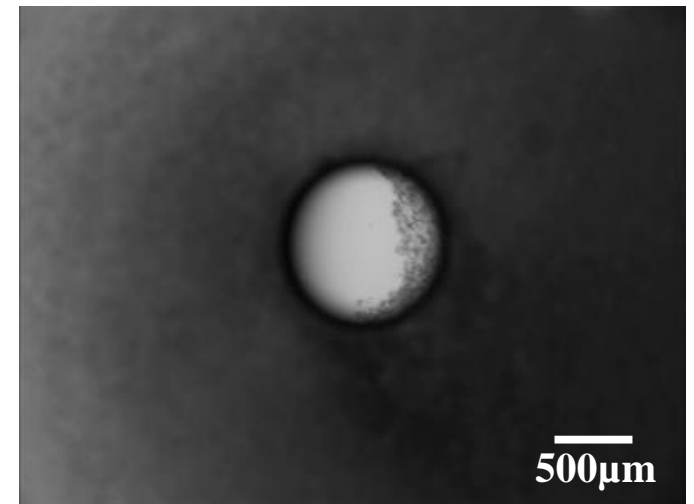

(b)

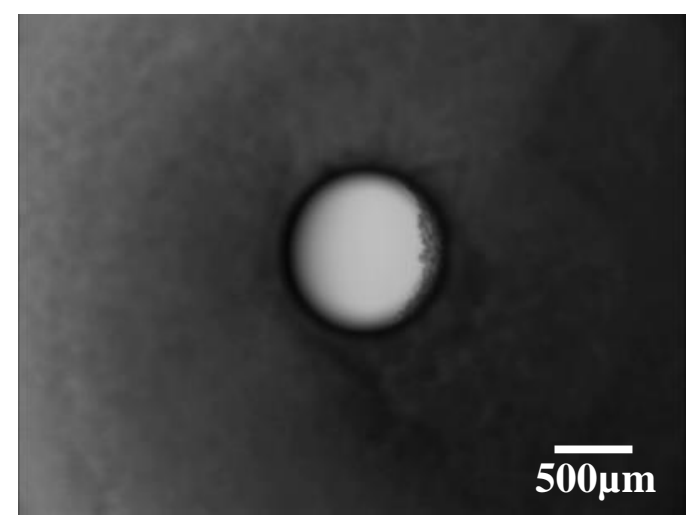

(d)

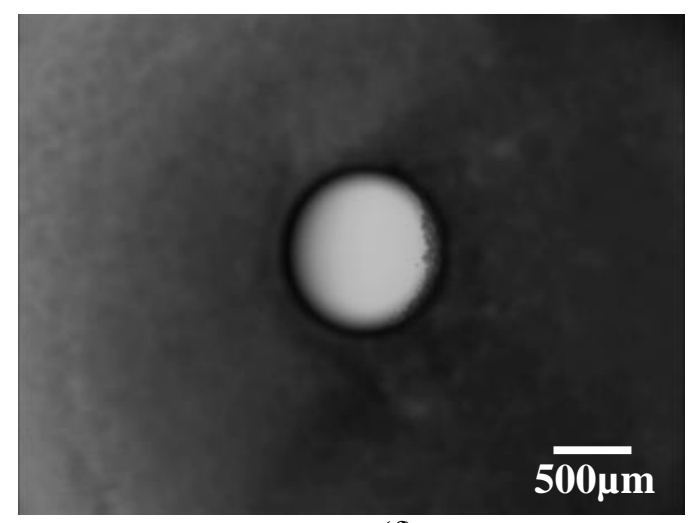

(f) 
Figure 9

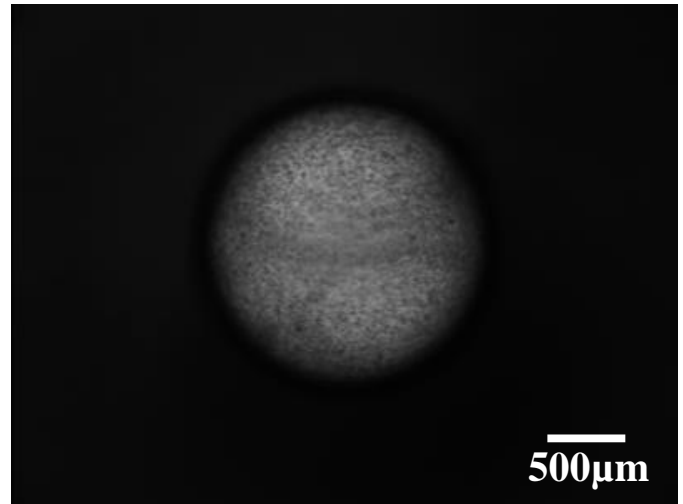

(a)

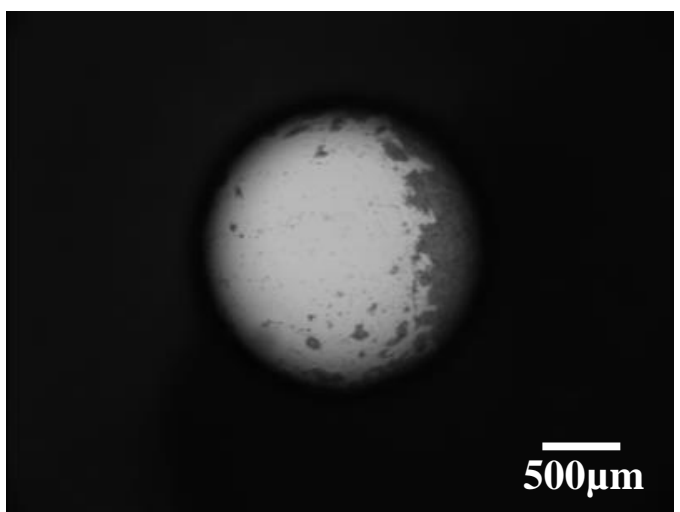

(c)

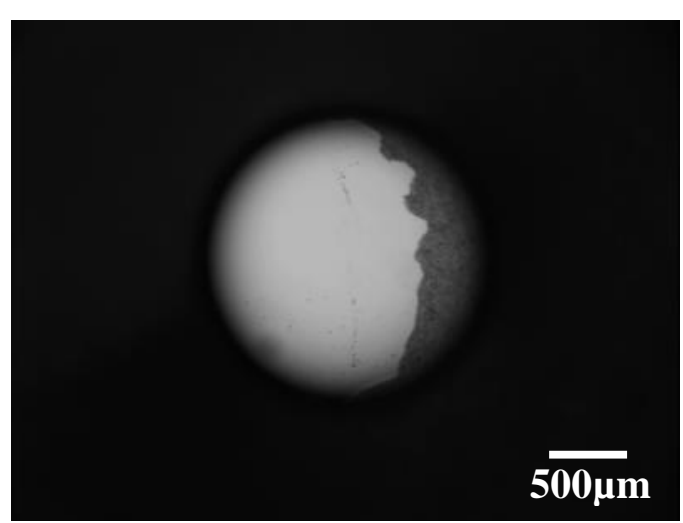

(e)

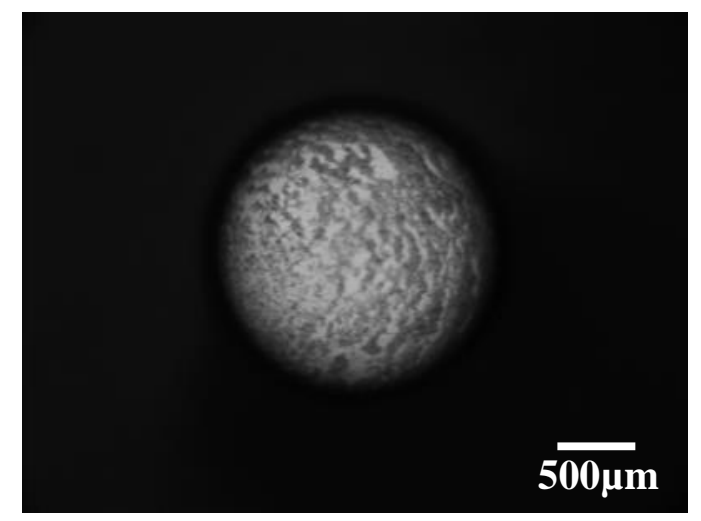

(b)

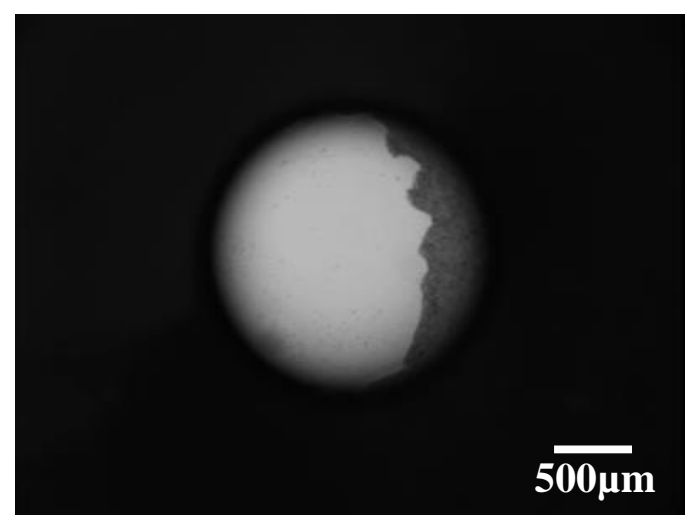

(d)

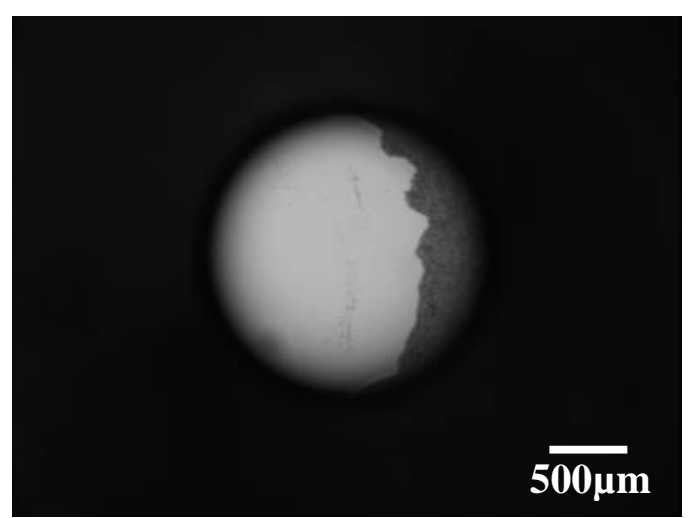

(f) 
Figure 10

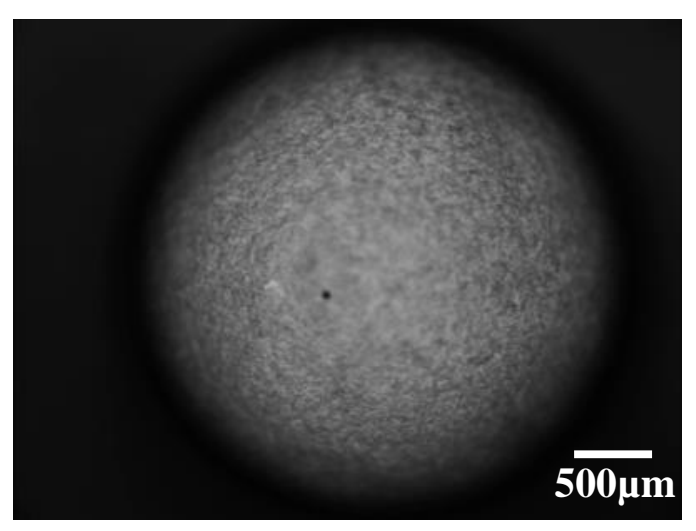

(a)

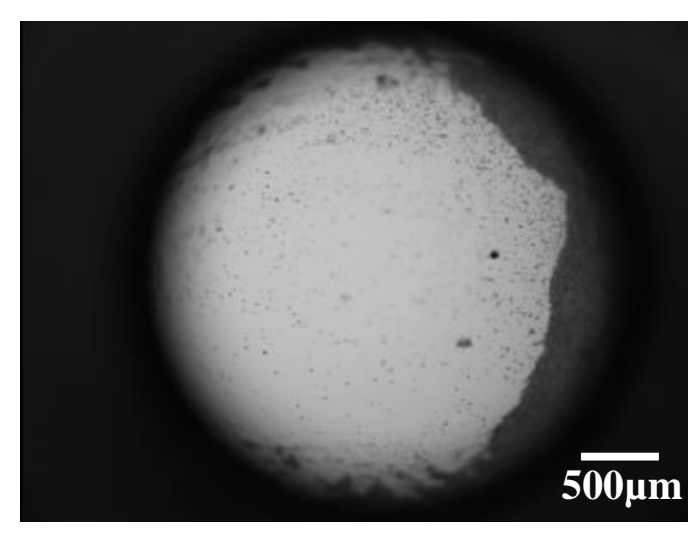

(c)

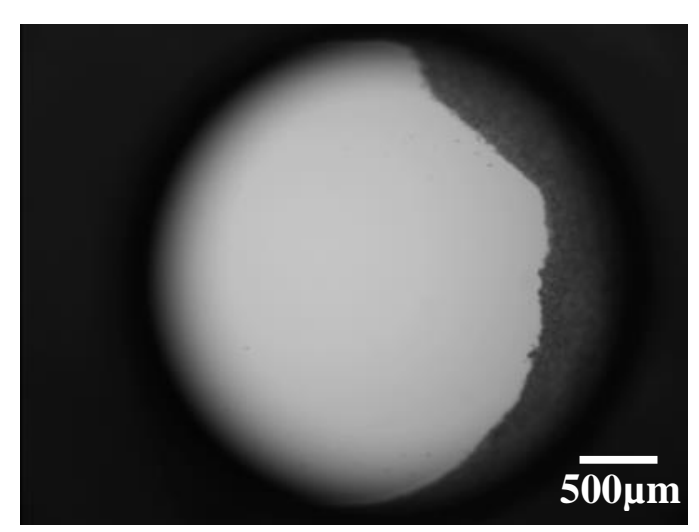

(e)

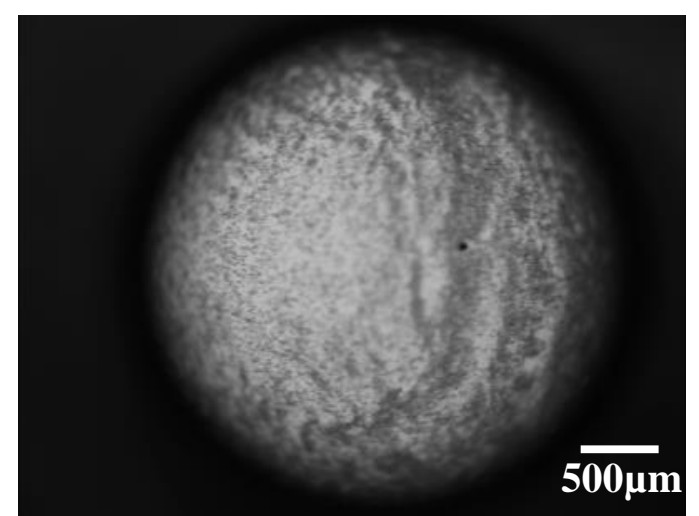

(b)

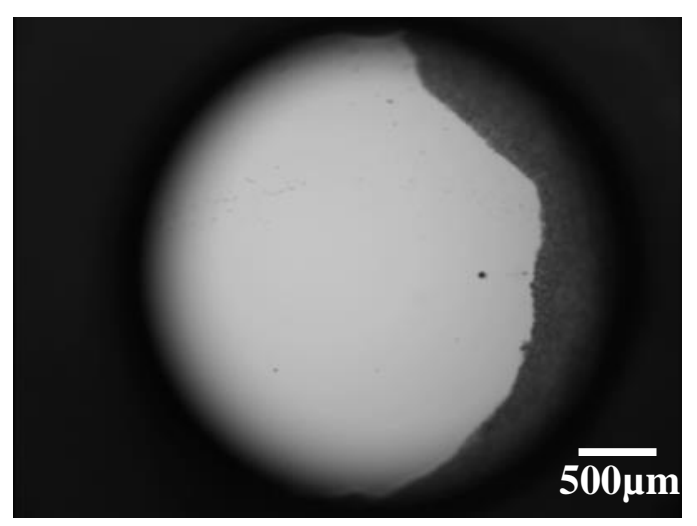

(d)

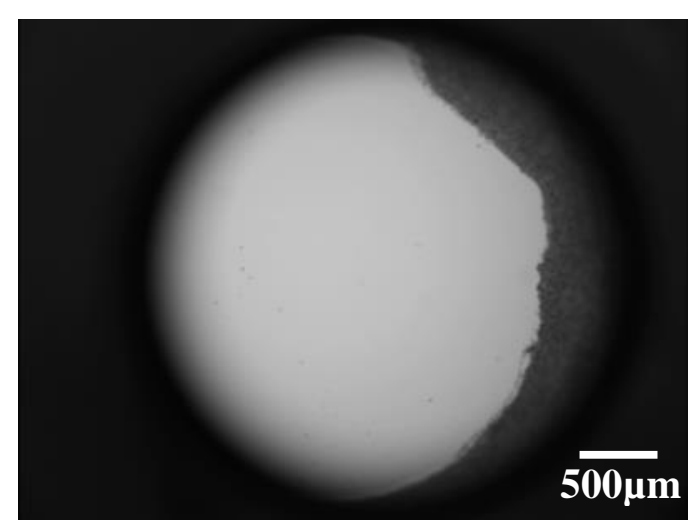

(f) 